\title{
Comparison of clinical and echocardiographic outcomes and quality of life in patients with severe mitral regurgitation treated by MitraClip implantation or treated conservatively
}

\author{
Agata Krawczyk-Ożóg ${ }^{1,2}$, Zbigniew Siudak ${ }^{1}$, Danuta Sorysz ${ }^{1}$, Mateusz K. Hołda ${ }^{2,3}$, Anna Płotek ${ }^{1}$, \\ Artur Dziewierz ${ }^{1,4}$, Andrzej Gackowski ${ }^{5}$, Dariusz Dudek ${ }^{1,4}$ \\ ${ }^{1} 2^{\text {nd }}$ Department of Cardiology and Cardiovascular Interventions, University Hospital, Krakow, Poland \\ ${ }^{2}$ HEART - Heart Embryology and Anatomy Research Team, Department of Anatomy, Jagiellonian University Medical College, Krakow, Poland \\ ${ }^{3}$ Department of Cardiac and Vascular Diseases, Institute of Cardiology, Jagiellonian University Medical College, Krakow, Poland \\ ${ }^{4} 2^{\text {nd }}$ Department of Cardiology, Institute of Cardiology, Jagiellonian University Medical College, Krakow, Poland \\ ${ }^{5}$ Department of Coronary Artery Disease and Heart Failure, John Paul II Hospital, Jagiellonian University Medical College, Krakow, Poland
}

Adv Interv Cardiol 2018; 14, 3 (53): 291-298

DOI: https://doi.org/10.5114/aic.2018.78334

\begin{abstract}
A bstract
Introduction: The most common alternative method of treatment for patients with severe mitral regurgitation (MR) is the implantation of a MitraClip device.

Aim: To evaluate clinical and echocardiographic outcomes and quality of life (QoL) in patients with severe secondary MR, disqualified from surgical intervention, treated by implantation of a MitraClip in comparison to conservative therapy.

Material and methods: A total of 33 patients were included. Patients were stratified by treatment method: group A, MitraClip implantation $(n=10)$; group B, conservative treatment $(n=23)$. Clinical, echocardiographic, and QoL (EQ-5D-3L, SF-12v2 Health Survey) characteristics were compared at baseline and at follow-up of $8.0 \pm 2.3$ months.

Results: In group A, 2 deaths were observed: one patient died 7 days after MitraClip implantation, and the second patient died 4 months after the procedure. No cases of rehospitalization were reported. In group B, 4 (17.4\%) deaths and 6 (26.1\%) hospitalizations were reported. After MitraClip implantation a significant reduction of the NYHA class $(p=0.02)$, decrease in grade of MR $(p=0.01)$, vena contracta width $(p=0.006)$, effective regurgitant orifice area (EROA) $(p=0.003)$, regurgitant volume $(p=0.03)$ and end-diastolic left ventricle diameter $(p=0.02)$ as well as an improvement in QoL were reported. There were no significant changes in the NYHA class and QoL in the group treated conservatively. In those patients, we observed increased intercommissural mitral annulus diameter $(p=0.03)$, left atrium diameter $(p=0.002)$, and right ventricle dimension $(p=0.008)$, more severe tricuspid regurgitation $(p=0.02)$ and lower mitral annular plane systolic excursion $(p=0.01)$.

Conclusions: Patients with severe secondary MR treated with the MitraClip achieved a significant reduction in symptoms and MR grade, as well as an improvement in QoL, as compared to patients treated conservatively.
\end{abstract}

Key words: MitraClip, heart failure, mitral regurgitation, quality of life.

Su m mary

In this study, we evaluated the effect of MitraClip implantation on severe functional mitral regurgitation, a procedure that is not fully established as beneficial for this etiology of mitral regurgitation. We revealed that percutaneous edge-to-edge mitral valve repair in comparison to conservative therapy improves the clinical condition of the patients, reduces mitral regurgitation grade and increases the quality of life. Large randomized studies are necessary to fully assess the clinical impact of MitraClip implantation in patients with severe functional mitral regurgitation.

\section{Introduction}

The mitral valve is one of the most complicated mechanical arrangements in the human body and should be analyzed as a complex consisting of the annulus, leaflets, commissures, tendinous cords, papillary muscles, and the left atrial and ventricular walls [1, 2]. Damage of even

Corresponding author:

Agata Krawczyk-Ożóg MD, 2 ${ }^{\text {nd }}$ Department of Cardiology and Cardiovascular Interventions, 17 Kopernika, 31-501 Krakow, Poland, phone: +48 1242471 70, fax: +48 1242471 80, e-mail: krawczyk.ozog@gmail.com

Received: 1.06.2018, accepted: 24.07.2018. 
one part of them may significantly affect the function of the valve and cause mitral regurgitation (MR), which is one of the most prevalent valvular heart diseases. According to etiology, MR can be classified as primary, due to intrinsic valvular disease, and secondary (functional), without obvious structural abnormalities of the valve, but associated with severe left ventricle (LV) dysfunction especially due to coronary artery disease (ischemic MR) or idiopathic myocardial disease (non-ischemic MR).

In recent years we have observed the rapid development of surgical and less invasive percutaneous mitral valve repair procedures. The most common alternative method of treatment for patients with severe MR with very high surgical risk or with contraindications to surgical mitral valve replacement or repair is transcatheter edge-to-edge mitral valve repair using the MitraClip device (MitraClip, Abbott Vascular, Menlo Park, CA, USA) [3]. Current guidelines advise transcatheter mitral valve repair for severely symptomatic patients despite optimal medical therapy with chronic severe primary MR with favorable anatomy for this procedure and a reasonable life expectancy, but with prohibitive surgical risk because of severe comorbidities (American Guidelines - recommendation IIb, B; European Guidelines - recommendation IIb, C) $[4,5]$. In contrast, only the European Guidelines recommend the MitraClip procedure for patients with severe secondary $M R$ (recommendation IIb, C) [4, 6], judging that it is associated with a low procedural risk and absence of severe complications and may provide a short-term improvement in functional condition and left ventricle function $[7,8]$.

\section{Aim}

Thus, our study aimed to evaluate clinical and echocardiographic outcomes and quality of life (QoL) in highrisk patients with severe secondary $M R$, disqualified from surgical intervention, treated by implantation of a MitraClip device in comparison with patients treated conservatively.

\section{Material and methods}

\section{Study population}

This study was approved by the Bioethics Committee of the Jagiellonian University Medical College, Krakow, Poland (No. 122.6120.292.2015). We analyzed all patients with MR admitted to the $2^{\text {nd }}$ Department of Cardiology and Cardiovascular Interventions, University Hospital in Krakow between January 2016 and January 2017. We included 33 consecutive patients (46\% females) with severe secondary $M R$ recognized during transthoracic echocardiography (TTE) according to the recommendations for the echocardiographic assessment of native valvular regurgitation [9]. All patients were disqualified from surgical mitral valve replacement or repair by a local heart team, because of very high surgical risk or serious contraindications. Patients were assigned to two groups: group $\mathrm{A}(n=10)$ patients who have undergone a MitraClip procedure and group $\mathrm{B}(n=23)$ patients treated conservatively. In group A, 4 patients were treated with one clip, and 6 patients were treated with two clips. The group B subjects were patients who were waiting for a MitraClip procedure or with some contraindications for MitraClip due to anatomical reasons or patients who did not agree to MitraClip implantation.

The assessment of clinical, echocardiographic, and QoL characteristics was performed at baseline and mean $8.0 \pm 2.3$ months following the procedure (group A) or after inclusion in the study (group B) $(8.1 \pm 2.4$ vs. $8.0 \pm 2.4$; $p=0.9$ ). Evaluated clinical outcomes were: symptoms in New York Heart Association (NYHA) functional class, major adverse cardiac events (MACE: death, stroke, myocardial infarction, vascular complications, arrhythmias and conduction abnormalities, reoperation, thromboembolic complications). Additionally, the number of hospitalizations due to heart failure decompensation was assessed.

\section{Echocardiographic assessment}

All patients underwent TTE at baseline and during follow-up. In addition, severe MR was confirmed using two-dimensional and three-dimensional transesophageal echocardiography (TEE) at baseline, which allowed better visualization of mitral valve anatomy and mechanism of the valve disease. All TTE and TEE examinations were performed using Vivid E9 (GE Healthcare, Waukesha, WI, USA). The post-processing and study evaluation were performed using a dedicated workstation (EchoPAC, GE Healthcare, Waukesha, WI, USA). All linear measurements were taken using virtual calipers. The echocardiographic assessments of the mitral regurgitation were done according to the current guidelines $[9,10]$.

In particular, we assessed and measured:

- severity of MR: vena contracta width (in case multiple jets - vena contracta of dominant jet), regurgitant volume, effective regurgitant orifice area (EROA),

- morphometric mitral valve parameters: systolic tenting area, systolic tenting height. Mitral annulus diameters: aorto-mural, annulus/anterior leaflet ratio in parasternal long-axis TTE view and intercommissural diameter in the modified apical two-chamber view,

- left ventricle (LV) geometry and functions: end-diastolic and end-systolic LV diameters in parasternal long-axis, LV sphericity index in apical four-chamber view, major LV dimension in three-chamber view, LV ejection fraction, $\mathrm{d} p / \mathrm{d} t$ (calculated from the MR Doppler trace), mitral annular plane systolic excursion,

- atrial parameters: left atrium diameter in parasternal long axis, left atrium indexed volume, right atrium area and indexed volume,

- other parameters associated with the right heart: right ventricle linear dimension (maximal transversal dimen- 
sion in the basal one third of right ventricle inflow at end-diastole), systolic pulmonary artery pressure, tricuspid annular plane systolic excursion.

\section{Quality of life assessment}

The QoL was assessed personally with the self-reported Polish validated version of the EQ-5D-3L questionnaire and SF-12v2 Health Survey (SF-12v2). The EQ$5 \mathrm{D}-3 \mathrm{~L}$ is a standardized instrument for measurement of health-related QoL, consisting of a descriptive system and the Visual Analog Scale. Respondents can score each domain representing various aspects of health: mobility, self-care, usual activities, pain/discomfort and anxiety/ depression, from one (no problems) to three (extreme problems) points $[11,12]$. The SF-12v2 is a multipurpose, short-form health survey with 12 questions that brings an eight-scale profile of functional health together with well-being, the preference-based Health Utility Index and two psychometrically based components: Physical and Mental Health Composite Summary (PCS, MCS) [13].

\section{Statistical analysis}

Quantitative variables were described using means and standard deviations. Categorical variables were presented as percentages. The Shapiro-Wilk test was used to determine whether the quantitative data were normally distributed. Direct comparison between groups was conducted using Student's $t$-test and the Mann-Whitney $U$ test. The Wilcoxon signed-rank test (for non-normal distribution of data) or paired Student's $t$-test (for normally distributed data) was applied for assessment of changes in particular dimensions of a questionnaire assessing QoL and echocardiographic parameters. We performed statistical analyses with Statistica v13 (StatSoft Inc., Tulsa, OK, USA). A $p$-value of $<0.05$ was considered to be statistically significant.

\section{Results \\ Baseline}

The mean age of the 33 included patients was 72.6 \pm 10.4 years. The average body mass index was 27.9 $\pm 4.5 \mathrm{~kg} / \mathrm{m}^{2}$ and mean body surface area was $1.9 \pm 0.2 \mathrm{~m}^{2}$. Baseline clinical characteristics of patients are shown in Table I. Patients from group A have a lower rate of previous coronary artery bypass grafting but a higher rate of cardiac resynchronization therapy, as compared to patients in group B $(p<0.05)$. No other differences in baseline characteristics were noted between groups. Mitral regurgitation in all cases was caused by restricted leaflet motion in systole (Carpentier IIIb). Additionally, in 21 cases (63.6\%) (7 patients from group A (70.0\%) and 14 from group B (60.9\%)) annular dilatation (Carpentier I) coexisted with restricted leaflet motion. At baseline echocardiography, groups differed only in LV sphericity index and mitral annular plane systolic excursion $(p<0.05)$, while no other differences were found (Table II). Baseline parameters of QoL assessed using EQ-5D-3L and SF12v2 questionnaires were comparable between groups (Table III, Figure 1).

\section{Follow-up}

In group A after implantation of the MitraClip device, 1 patient had a stroke 7 days after the procedure and died (1 patient, 10.0\%). Other periprocedural MACE were not reported. Four months after the procedure, another patient (10.0\%) died due to severe heart failure decompensation (other circumstances of death are unknown). Remaining patients from this group had no hospitalizations for cardiac reasons during follow-up. After MitraClip implantation a significant reduction in heart failure symptoms on the NYHA scale was observed $(p=0.02)$. A decrease in grade of MR $(p=0.01)$, vena contracta width $(p=0.006)$, EROA $(p=0.003)$, regurgitant volume $(p=0.03)$, and end-diastolic LV diameter $(p=0.02)$, as well as an increase in mean transvalvular mitral gradient $(p=0.03)$, was observed in patients after MitraClip implantation (Table II).

In group B we noted 4 (17.4\%) deaths at a mean of $5.0 \pm 2.8$ months after enrollment. The causes of death were: severe heart failure decompensation, complicated by pulmonary edema (3 patients, 13.0\%) and infection (1 patient, 4.3\%). Furthermore, a substantial number of hospitalizations caused by heart failure decompensation (4 patients, $17.4 \%$ ), chest pain (1 patient, 4.3\%), and deep vein thrombosis (1 patient, $4.3 \%$ ) were noted in group B. No reduction in heart failure symptoms was observed in patients treated conservatively $(p=0.4)$. In those patients, we observed an increased intercommissural mitral annulus diameter $(p=0.03)$, left atrium diameter $(p=0.002)$, right ventricle dimension $(p=0.008)$ and more severe tricuspid regurgitation $(p=0.02)$ together with lower mitral annular plane systolic excursion $(p=0.01)$ in TTE examination performed at follow-up in comparison with baseline (Table II).

At follow-up significantly lower MR $(p<0.001)$, vena contracta width $(p<0.001)$, EROA $(p=0.003)$, regurgitant volume $(p=0.007)$, right ventricle dimension $(p=0.02)$, and mean transvalvular mitral gradient $(p=0.01)$ were observed in group A as compared to group B (Table II).

Improvement in QoL after the intervention was confirmed in group A patients in the following domains of the SF12v2 questionnaire: Physical Functioning (32.5 \pm 6.6 vs. $41.3 \pm 5.9 ; p=0.03$ ), Role-Physical (34.2 \pm 6.0 vs. $40.5 \pm 6.4 ; p=0.04$ ), Role-Emotional (25.1 \pm 0.1 vs. 35.5 $\pm 9.6 ; p=0.04)$ and Physical Component Summary (34.7 \pm 6.2 vs. $42.6 \pm 5.6 ; p=0.04$ ). Additionally, the Health Utility Index in this group was significantly higher after the observation period ( $0.6 \pm 0.1$ vs. $0.7 \pm 0.1 ; p=0.04$ ) (Figure 1). We did not observe significant changes in results of the EQ-5D-3L questionnaire in group A (Table III). 
In group $B$, the results of the EQ-5D-3L, as well as the SF12v2, were comparable at both time points. No differences in changes of the EQ-5D-3L Visual Analogue Scale from baseline to follow-up were found in both groups (Table III).

At follow-up, in a direct comparison between groups, differences in parameters of QoL were noted in terms of self-care EQ-5D-3L ( $p=0.007)$, where all patients in group A reported "no problem" (Table III). Furthermore, higher scores were obtained in group $A$ in comparison to group $B$ in the Physical Functioning domain ( $41.3 \pm 5.9$ vs. $33.5 \pm 5.4 ; p=0.007$ ) and Physical Component Summary $(42.6 \pm 5.6$ vs. $37.0 \pm 4.3 ; p=0.01)$ of SF12v2 (Figure 1).

\section{Discussion}

Our study shows that percutaneous edge-to-edge mitral valve repair improves the clinical condition of the patients, expressed as a reduction in heart failure symptoms. However, we observed two deaths in patients with an implanted MitraClip device (20.0\%). On the other hand, there were no hospitalizations caused by heart failure decompensation in remaining patients after $\mathrm{Mi}$ traClip implantation, while, in contrast, these were reported in $17.4 \%$ of patients from group $B$.

In this study, we analyzed only symptomatic patients with severe secondary MR and severely depressed systolic LV function, disqualified from surgical treatment. Patients with heart failure with reduced ejection fraction and severe MR, with comorbidities or very high surgical risk, may be qualified for the MitraClip procedure. In clinical daily practice access to this new intervention is still very limited. Other methods of invasive treatment for such patients are not available. A meta-analysis by Chiarito et al. compared patients with functional and de-

Table I. Baseline clinical characteristics of patients

\begin{tabular}{|c|c|c|c|}
\hline Parameter & Group A $(n=10)$ & Group B $(n=23)$ & $P$-value \\
\hline Age (mean $\pm S D)$ [years] & $71.8 \pm 7.8$ & $73.0 \pm 11.5$ & 0.43 \\
\hline Coronary artery disease confirmed in angiography (\%) & 100.0 & 87.0 & 0.25 \\
\hline Previous myocardial infarction (\%) & 70.0 & 78.3 & 0.63 \\
\hline Previous percutaneous coronary intervention (\%) & 70.0 & 60.9 & 0.64 \\
\hline Previous coronary artery bypass grafting (\%) & 0.0 & 34.8 & $0.04^{*}$ \\
\hline Cardiac resynchronization therapy (\%) & 70.0 & 26.1 & $0.02^{*}$ \\
\hline Arterial hypertension (\%) & 80.0 & 87.0 & 0.64 \\
\hline Diabetes mellitus type II (\%) & 30.0 & 26.1 & 0.84 \\
\hline Atrial fibrillation (\%) & 60.0 & 60.9 & 0.98 \\
\hline Hyperlipidemia (\%) & 70.0 & 65.2 & 0.81 \\
\hline Ever-smoker (\%) & 20.0 & 52.2 & 0.10 \\
\hline Chronic kidney disease (\%) & 20.0 & 52.2 & 0.10 \\
\hline Chronic obstructive pulmonary disease (\%) & 30.0 & 8.7 & 0.13 \\
\hline Thyroid disease (\%) & 10.0 & 26.1 & 0.32 \\
\hline Previous stroke/transient ischemic attack (\%) & 30.0 & 13.0 & 0.27 \\
\hline NT-proBNP (mean \pm SD) [pg/ml] & $3132.3 \pm 2374.6$ & $3083.1 \pm 2913.1$ & 0.72 \\
\hline Body mass index (mean $\pm \mathrm{SD})\left[\mathrm{kg} / \mathrm{m}^{2}\right]$ & $29.4 \pm 3.7$ & $27.3 \pm 4.7$ & 0.15 \\
\hline Body surface area (mean \pm SD) $\left[m^{2}\right]$ & $1.9 \pm 0.1$ & $1.9 \pm 0.2$ & 0.32 \\
\hline EuroSCORE II (mean \pm SD) (\%) & $3.9 \pm 1.7$ & $6.2 \pm 3.8$ & 0.12 \\
\hline \multicolumn{4}{|l|}{ New York Heart Association (NYHA) class (\%): } \\
\hline I & 0.0 & 0.0 & 0.96 \\
\hline II & 10.0 & 8.7 & \\
\hline III & 70.0 & 73.9 & \\
\hline IV & 20.0 & 17.4 & \\
\hline
\end{tabular}

$N$-number of samples, SD - standard deviation, *statistically significant. 
Table II. Results of obtained echocardiographic data (mean \pm standard deviation) at baseline and during follow-up in groups A and B. Results do not include patients who died during the follow-up period (group A: $n=8$, group $B: n=19)$

\begin{tabular}{|c|c|c|c|c|c|c|c|c|}
\hline \multirow[t]{2}{*}{ Parameter } & \multicolumn{3}{|c|}{ Group A } & \multicolumn{3}{|c|}{ Group B } & \multirow{2}{*}{$\begin{array}{c}\text { Group } \\
\text { A vs. B } \\
\text { at baseline }\end{array}$} & \multirow{2}{*}{$\begin{array}{l}\text { Group } \\
\text { A vs. B at } \\
\text { follow-up }\end{array}$} \\
\hline & Baseline & Follow-up & $P$-value & Baseline & Follow-up & $P$-value & & \\
\hline \multicolumn{9}{|l|}{ Mitral regurgitation, $n(\%)$ : } \\
\hline Mild & 0 & $2(25.0)$ & \multirow[t]{4}{*}{$0.01^{*}$} & 0 & 0 & \multirow[t]{4}{*}{$>0.05$} & \multirow[t]{4}{*}{1.0} & \multirow[t]{4}{*}{$<0.001^{\star}$} \\
\hline Mild/moderate & 0 & $2(25.0)$ & & 0 & 0 & & & \\
\hline Moderate & 0 & $4(50.0)$ & & 0 & $1(5.3)$ & & & \\
\hline Severe & $8(100)$ & 0 & & 19 (100.0) & $18(94.7)$ & & & \\
\hline Vena contracta width [mm] & $6.6 \pm 0.9$ & $3.3 \pm 1.4$ & $0.006^{\star}$ & $7.2 \pm 1.2$ & $7.6 \pm 1.3$ & 0.1 & 0.4 & $<0.001^{*}$ \\
\hline Regurgitant volume [ml] & $37.6 \pm 13.8$ & $19.8 \pm 6.6$ & $0.03^{*}$ & $38.4 \pm 9.4$ & $39.5 \pm 13.0$ & 0.8 & 0.9 & $0.007^{*}$ \\
\hline $\begin{array}{l}\text { Effective regurgitant orifice } \\
\text { area }\left[\mathrm{mm}^{2}\right]\end{array}$ & $25.1 \pm 7.7$ & $13.0 \pm 5.3$ & $0.003^{*}$ & $26.1 \pm 7.3$ & $27.2 \pm 8.7$ & 0.3 & 0.8 & $0.003^{*}$ \\
\hline Systolic tenting area $\left[\mathrm{cm}^{2}\right]$ & $3.5 \pm 0.6$ & - & - & $3.5 \pm 1.1$ & $3.5 \pm 1.4$ & 0.7 & 0.9 & - \\
\hline Systolic tenting height [mm] & $6.6 \pm 2.3$ & - & - & $8.8 \pm 2.6$ & $9.4 \pm 3.2$ & 0.4 & 0.08 & - \\
\hline $\begin{array}{l}\text { Intercommissural mitral annulus } \\
\text { diameter }[\mathrm{mm}]\end{array}$ & $40.0 \pm 6.9$ & $39.0 \pm 6.2$ & 0.3 & $38.7 \pm 6.7$ & $40.5 \pm 5.9$ & $0.03^{*}$ & 1.0 & 0.7 \\
\hline $\begin{array}{l}\text { Aorto-mural mitral annulus } \\
\text { diameter }[\mathrm{mm}]\end{array}$ & $42.3 \pm 2.5$ & $40.7 \pm 1.2$ & 0.2 & $39.7 \pm 5.7$ & $39.7 \pm 5.7$ & 1.0 & 0.5 & 1.0 \\
\hline $\begin{array}{l}\text { Aorto-mural mitral annulus/ } \\
\text { anterior leaflet ratio }\end{array}$ & $1.98 \pm 0.07$ & $1.91 \pm 0.09$ & 0.2 & $1.97 \pm 0.4$ & $1.98 \pm 0.5$ & 0.8 & 0.95 & 0.9 \\
\hline End-diastolic LV diameter [mm] & $70.8 \pm 7.8$ & $67.0 \pm 8.0$ & $0.02^{*}$ & $65.6 \pm 12.0$ & $67.0 \pm 11.4$ & 0.09 & 0.7 & 0.97 \\
\hline End-systolic LV diameter [mm] & $61.6 \pm 9.1$ & $59.8 \pm 11.1$ & 0.4 & $57.2 \pm 10.7$ & $55.8 \pm 13.7$ & 0.5 & 0.3 & 0.5 \\
\hline LV sphericity index & $1.3 \pm 0.1$ & $1.4 \pm 0.02$ & 0.7 & $1.5 \pm 0.2$ & $1.5 \pm 0.2$ & 1.0 & $0.04^{\star}$ & 0.2 \\
\hline $\begin{array}{l}\text { Major dimension of LV in } \\
\text { three-chamber view [ } \mathrm{mm}]\end{array}$ & $90.3 \pm 18.1$ & $92.0 \pm 15.9$ & 0.8 & $87.0 \pm 11.6$ & $87.6 \pm 10.4$ & 0.9 & 0.7 & 0.6 \\
\hline LV ejection fraction (\%) & $26.1 \pm 9.4$ & $25.4 \pm 8.5$ & 0.7 & $31.8 \pm 10.9$ & $31.6 \pm 13.2$ & 0.9 & 0.18 & 0.2 \\
\hline $\mathrm{d} p / \mathrm{d} t \max$ & $687.1 \pm 178.8$ & $782.0 \pm 248.7$ & 0.2 & $888.6 \pm 343.6$ & $836.4 \pm 194.3$ & 0.6 & 0.4 & 0.7 \\
\hline LA diameter $[\mathrm{cm}]$ & $54.3 \pm 6.2$ & $52.1 \pm 4.8$ & 0.29 & $55.6 \pm 8.2$ & $60.5 \pm 10.5$ & $0.002^{*}$ & 0.7 & 0.05 \\
\hline LA indexed volume $\left[\mathrm{ml} / \mathrm{m}^{2}\right]$ & $80.7 \pm 23.5$ & $60.5 \pm 30.8$ & 0.3 & $84.4 \pm 34.7$ & $97.6 \pm 43.8$ & 0.08 & 0.7 & 0.1 \\
\hline $\mathrm{RA}$ area $\left[\mathrm{cm}^{2}\right]$ & $24.8 \pm 7.6$ & $22.9 \pm 5.3$ & 0.5 & $28.2 \pm 7.3$ & $29.8 \pm 7.8$ & 0.2 & 0.4 & 0.09 \\
\hline RA indexed volume $\left[\mathrm{ml} / \mathrm{m}^{2}\right]$ & $45.1 \pm 14.8$ & $37.6 \pm 14.9$ & 0.6 & $55.5 \pm 25.8$ & $65.6 \pm 25.5$ & 0.2 & 0.5 & 0.1 \\
\hline RV dimension [cm] & $41.8 \pm 6.6$ & $38.3 \pm 6.9$ & 0.3 & $43.8 \pm 5.8$ & $47.7 \pm 6.1$ & $0.008^{*}$ & 0.96 & $0.02^{*}$ \\
\hline $\begin{array}{l}\text { Systolic pulmonary artery } \\
\text { pressure }[\mathrm{mm} \mathrm{Hg}]\end{array}$ & $62.0 \pm 18.3$ & $53.4 \pm 18.3$ & 0.4 & $56.4 \pm 17.5$ & $59.8 \pm 20.1$ & 0.6 & 0.5 & 0.5 \\
\hline TAPSE $[\mathrm{mm}]$ & $14.0 \pm 2.9$ & $17.7 \pm 5.9$ & 0.1 & $15.8 \pm 3.0$ & $14.8 \pm 2.9$ & 0.3 & 0.2 & 0.2 \\
\hline MAPSE $[\mathrm{mm}]$ & $9.3 \pm 1.7$ & $10.7 \pm 3.2$ & 0.2 & $12.2 \pm 1.9$ & $10.1 \pm 2.2$ & $0.01^{*}$ & $0.02^{*}$ & 0.8 \\
\hline $\begin{array}{l}\text { Mean transvalvular mitral } \\
\text { gradient [mm Hg] }\end{array}$ & $2.2 \pm 1.0$ & $4.7 \pm 0.8$ & $0.03^{*}$ & $2.4 \pm 1.3$ & $2.7 \pm 1.3$ & 0.05 & 0.8 & $0.01^{*}$ \\
\hline \multicolumn{9}{|l|}{ Tricuspid regurgitation: } \\
\hline Mild & $3(37.5 \%)$ & 6 & 0.4 & $10(52.6 \%)$ & $5(26.3 \%)$ & $0.02^{*}$ & 0.76 & 0.08 \\
\hline Moderate & $5(62.5 \%)$ & 1 & & $5(26.3 \%)$ & $9(47.4 \%)$ & & & \\
\hline Severe & 0 & 1 & & $4(21.1 \%)$ & $5(26.3 \%)$ & & & \\
\hline
\end{tabular}

$N$ - number of samples, LV - left ventricle, RV - right ventricle, LA - left atrium, RA - right atrium, MAPSE - mitral annular plane systolic excursion, TAPSE - tricuspid annular plane systolic excursion, *statistically significant. 
Table III. Results of EQ-5D-3L questionnaire $(n, \%)$ at baseline and during follow-up in groups A and B. Results do not include patients who died during the observation period (group A: $n=8$, group B: $n=19$ )

\begin{tabular}{|c|c|c|c|c|c|c|c|c|}
\hline \multirow[t]{2}{*}{ Variable } & \multicolumn{3}{|c|}{ Group A } & \multicolumn{3}{|c|}{ Group B } & \multirow{2}{*}{$\begin{array}{l}\text { Group A } \\
\text { vs. B at } \\
\text { baseline }\end{array}$} & \multirow{2}{*}{$\begin{array}{l}\text { Group A } \\
\text { vs. B at } \\
\text { follow-up }\end{array}$} \\
\hline & Baseline & Follow-up & $P$-value & Baseline & Follow-up & $P$-value & & \\
\hline \multicolumn{9}{|l|}{ Mobility, EQ-5D-3L: } \\
\hline No problem & 0 & $1(12.5 \%)$ & \multirow[t]{3}{*}{0.2} & 0 & $2(10.5 \%)$ & \multirow[t]{3}{*}{0.2} & \multirow[t]{3}{*}{0.2} & \multirow[t]{3}{*}{0.7} \\
\hline Some problems & $6(75.0 \%)$ & $7(87.5 \%)$ & & $18(94.7 \%)$ & $16(84.2 \%)$ & & & \\
\hline Extreme problems & $2(25.0 \%)$ & 0 & & $1(5.3 \%)$ & $1(5.3 \%)$ & & & \\
\hline \multicolumn{9}{|l|}{ Self-Care, EQ-5D-3L: } \\
\hline No problem & $4(50.0 \%)$ & $8(100.0 \%)$ & \multirow[t]{3}{*}{0.07} & $5(26.3 \%)$ & $8(42.1 \%)$ & \multirow[t]{3}{*}{0.1} & \multirow[t]{3}{*}{0.2} & \multirow[t]{3}{*}{$0.007^{\star}$} \\
\hline Some problems & $4(50.0 \%)$ & 0 & & $13(68.4 \%)$ & $11(57.9 \%)$ & & & \\
\hline Extreme problems & 0 & 0 & & $1(5.3 \%)$ & 0 & & & \\
\hline \multicolumn{9}{|l|}{ Usual Activities, EQ-5D-3L: } \\
\hline No problem & $2(25.0 \%)$ & $4(50.0 \%)$ & \multirow[t]{3}{*}{0.07} & $2(10.5 \%)$ & $5(26.3 \%)$ & \multirow[t]{3}{*}{0.1} & \multirow[t]{3}{*}{0.7} & \multirow[t]{3}{*}{0.2} \\
\hline Some problems & $4(50.0 \%)$ & $4(50.0 \%)$ & & $13(68.4 \%)$ & $11(57.9 \%)$ & & & \\
\hline Extreme problems & $2(25.0 \%)$ & 0 & & $4(21.1 \%)$ & $3(15.8 \%)$ & & & \\
\hline \multicolumn{9}{|l|}{ Pain/Discomfort, EQ-5D-3L: } \\
\hline No problem & $3(37.5 \%)$ & $5(62.5 \%)$ & \multirow[t]{3}{*}{0.2} & $6(31.6 \%)$ & $6(31.6 \%)$ & \multirow[t]{3}{*}{0.7} & \multirow[t]{3}{*}{0.7} & \multirow[t]{3}{*}{0.2} \\
\hline Some problems & $5(62.5 \%)$ & $3(37.5 \%)$ & & $12(63.2 \%)$ & $13(68.4 \%)$ & & & \\
\hline Extreme problems & 0 & 0 & & $1(5.3 \%)$ & 0 & & & \\
\hline \multicolumn{9}{|l|}{ Anxiety/Depression, EQ-5D-3L: } \\
\hline No problem & $3(37.5 \%)$ & $4(50.0 \%)$ & \multirow[t]{3}{*}{0.6} & $4(21.1 \%)$ & $9(47.4 \%)$ & \multirow[t]{3}{*}{0.2} & \multirow[t]{3}{*}{0.4} & \multirow[t]{3}{*}{0.8} \\
\hline Some problems & $5(62.5 \%)$ & $4(50.0 \%)$ & & $15(78.9 \%)$ & $9(47.4 \%)$ & & & \\
\hline Extreme problems & 0 & 0 & & 0 & $1(5.3 \%)$ & & & \\
\hline $\begin{array}{l}\text { EQ Visual Analogue Scale } \\
\text { (mean } \pm \text { standard deviation) }\end{array}$ & $39.4 \pm 14.5$ & $48.1 \pm 23.0$ & 0.2 & $39.2 \pm 13.9$ & $40.8 \pm 12.8$ & 0.7 & 0.98 & 0.3 \\
\hline
\end{tabular}

generative MR treated by percutaneous edge-to-edge repair and concluded that this method is an efficacious and safe option in patients with both types of mitral valve disease [14]. A few more studies reported better survival after transcatheter mitral valve repair compared with conservative treatment in patients with LV dysfunction and secondary MR $[15,16]$. However, the authors emphasized that large, randomized studies are necessary to fully assess the clinical impact of the procedure in these two different MR etiologies.

Our results are convergent with other studies, which also showed an improvement in the severity of MR assessed by echocardiography in patients with an implanted MitraClip device compared with baseline [17-21]. In addition, MitraClip implantation induces significant reverse remodeling of $\mathrm{LV}$, which is substantial in advanced systolic heart failure and bring clinical benefits for these patients [15, 22]. In our study, we also observed a reduction of end-diastolic LV diameter after the intervention, but other LV parameters remained unchanged at follow-up.

Possible mechanisms by which ischemia can cause mitral regurgitation include asymmetric annular dilatation. Percutaneous mitral valve repair with the MitraClip has proved to reduce the size and area of the mitral valve annulus [23]. Our baseline and follow-up mitral annulus diameters and annulus/anterior leaflet ratio values confirmed annular dilatation associated with MR. In the group treated conservatively intercommissural mitral annulus diameter increased during the follow-up period, which was not observed in the group with the MitraClip.

The QoL assessment is an essential component in evaluating the efficacy of all the benefits obtained after the procedure. Previous studies showed that the MitraClip provides improvements in physical capacity, physical and mental functioning and disease-specific QoL in the majority of patients, but huge between-study heterogeneity was observed between individual studies [24]. The 
SF12v2 determines whether the scores for the PCS, MCS and particular health domain scales deviate from what is considered the average range for the U.S. general population [13]. Mean pre-procedural scores of our patients showed severe impairment of perceived QoL, not only in PCS and MCS scores but also in particular evaluated areas. It is important to note that QoL improvement is observed only in patients with interventional therapy and mainly focuses on PCS (Figure 1).

\section{Limitations}

The main limitation of this study is the relatively small sample size that is associated with the limited number of MitraClip procedures performed in our center. No details about the technique of MitraClip implantation were collected. On the other hand, the sample size was too small to assess any relationship between implantation technique and achieved outcomes. Other limitations are related to the single-center registry nature of this study. Moreover, non-disease-specific instruments for QoL assessments were used. However, we believe that these limitations do not impede our analysis and presented results.

\section{Conclusions}

Patients with severe secondary MR treated with the MitraClip system achieved a significant reduction of symptoms, MR grade and end-diastolic LV diameter during follow-up. In contrast, patients who remained on conservative therapy showed a higher incidence of hospitalization for heart failure, and increased intercommissural mitral annulus diameter, left atrium diameter, and right ventricle dimension, as well as more severe tricuspid regurgitation. Furthermore, a significant improvement in the QoL assessed by SF12v2 was observed after percutaneous edge-to-edge repair in comparison to conservative therapy.

\section{Acknowledgments}

This study was supported by the statutory funds of the Jagiellonian University Medical College (K/ZDS/006439), Krakow, Poland.

\section{Conflict of interest}

The authors declare no conflict of interest.

\section{References}

1. Krawczyk-Ożóg A, Hołda MK, Sorysz D, et al. Morphologic variability of the mitral valve leaflets. J Thorac Cardiovasc Surg 2017; 154: 1927-35.

2. Krawczyk-Ożóg A, Hołda MK, Bolechała F, et al. Anatomy of the mitral sub-valvular apparatus. J Thorac Cardiovasc Surg 2018; 155: 2002-10.

3. Nyman CB, Mackensen GB, Jelacic S, et al. Transcatheter mitral valve repair using the edge-to-edge clip. J Am Soc Echocardiogr 2018; 31: 434-53.
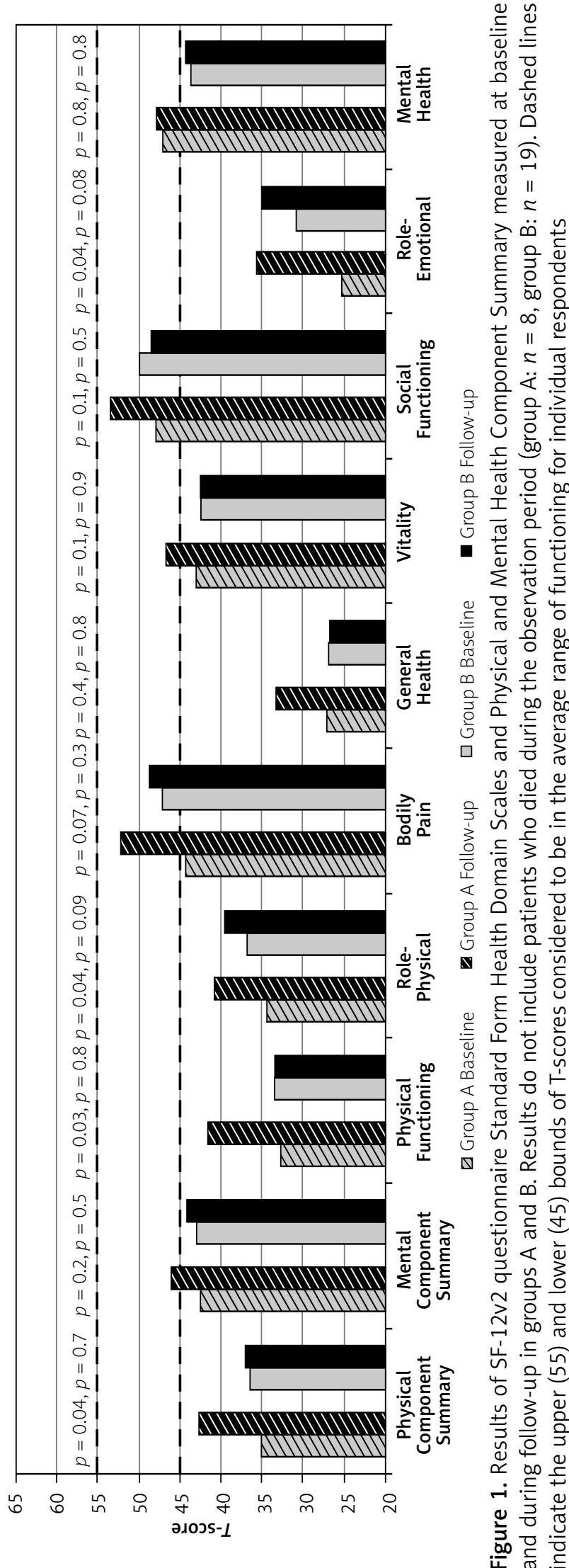
4. Baumgartner H, Falk V, Bax JJ, et al. 2017 ESC/EACTS Guidelines for the management of valvular heart disease. Eur Heart J 2017; 38: 2739-91.

5. Nishimura RA, Otto CM, Bonow RO, et al. 2017 AHA/ACC Focused Update of the 2014 AHA/ACC Guideline for the Management of Patients with Valvular Heart Disease: A Report of the American College of Cardiology/American Heart Association Task Force on Clinical Practice Guidelines. Circulation 2017; 135: e1159-95.

6. Orban M, Hausleiter J, Vascular A, Park M. Edge-to-edge mitral valve repair: solid data and a prosperous future. Heart 2018; 104: 280-81.

7. Feldman T, Foster E, Glower DD, et al. Percutaneous repair or surgery for mitral regurgitation. N Engl J Med 2011; 364: 1395-406.

8. Franzen O, Baldus S, Rudolph V, et al. Acute outcomes of MitraClip therapy for mitral regurgitation in high-surgical-risk patients: emphasis on adverse valve morphology and severe left ventricular dysfunction. Eur Heart J 2010; 31: 1373-81.

9. Lancellotti P, Tribouilloy C, Hagendorff A, et al. Recommendations for the echocardiographic assessment of native valvular regurgitation: an executive summary from the European Association of Cardiovascular Imaging. Eur Heart J Cardiovasc Imaging 2013; 14: 611-44.

10. Lang RM, Badano LP, Mor-Avi V, et al. Recommendations for cardiac chamber quantification by echocardiography in adults: an update from the American society of echocardiography and the European association of cardiovascular imaging. Eur Heart J Cardiovasc Imaging 2015; 16: 233-71.

11. Brooks R. EuroQol: the current state of play. Health Policy [Internet] 1996; 37: 53-72.

12. EuroQol Group. EuroQol - a new facility for the measurement of health-related quality of life. Health Policy 1990; 16: 199-208.

13. Mark M. User's Manual for the SF-12v2 Health Survey, Third Edition. 2012.

14. Chiarito M, Pagnesi M, Martino EA, et al. Outcome after percutaneous edge-to-edge mitral repair for functional and degenerative mitral regurgitation: a systematic review and meta-analysis. Heart 2017; 104: 306-12.

15. Giannini C, Petronio AS, De Carlo $M$, et al. Integrated reverse left and right ventricular remodelling after MitraClip implantation in functional mitral regurgitation: an echocardiographic study. Eur Hear J Cardiovasc Imaging 2014; 15: 95-103.

16. Swaans MJ, Bakker ALM, Alipour A, et al. Survival of transcatheter mitral valve repair compared with surgical and conservative treatment in high-surgical-risk patients. JACC Cardiovasc Interv 2014; 7: 875-81.

17. Chan $\mathrm{PH}$, She HL, Alegria-Barrero E, et al. Real-world experience of MitraClip for treatment of severe mitral regurgitation. Circ J 2012; 76: 2488-93.

18. Braun D, Lesevic $H$, Orban $M$, et al. Percutaneous edge-to-edge repair of the mitral valve in patients with degenerative versus functional mitral regurgitation. Catheter Cardiovasc Interv 2014; 84: 137-46.

19. Maisano F, Franzen O, Baldus S, et al. Percutaneous mitral valve interventions in the real world: early and 1-year results from the ACCESS-EU, a prospective, multicenter, nonrandomized post-approval study of the MitraClip therapy in Europe. J Am Coll Cardiol 2013; 62: 1052-61.

20. Nickenig G, Estevez-Loureiro R, Franzen O, et al. Percutaneous mitral valve edge-to-edge repair: in-hospital results and 1-year follow-up of 628 patients of the 2011-2012 Pilot European Sentinel Registry. J Am Coll Cardiol 2014; 64: 875-84.
21. Glower DD, Kar S, Trento A, et al. Percutaneous mitral valve repair for mitral regurgitation in high-risk patients: results of the EVEREST II study. J Am Coll Cardiol 2014; 64: 172-81.

22. Franzen O, van der Heyden J, Baldus S, et al. MitraClip ${ }^{\circledR}$ therapy in patients with end-stage systolic heart failure. Eur J Heart Fail 2011; 13: 569-76.

23. Benito-González T, Estevez R, Garrote C, et al. TCT-581 Impact of severe annular dilatation in the recurrence of mitral regurgitation after percutaneous edge-to-edge mitral valve repair. J Am Coll Cardiol 2017; 70: B241.

24. Iliadis C, Lee S, Kuhr K, et al. Functional status and quality of life after transcatheter mitral valve repair: a prospective cohort study and systematic review. Clin Res Cardiol 2017; 106: 1005-17. 